\title{
Higher Fees Paid To US Physicians Drive Higher Spending For Physician Services Compared To Other Countries
}

ABSTRACT Higher health care prices in the United States are a key reason that the nation's health spending is so much higher than that of other countries. Our study compared physicians' fees paid by public and private payers for primary care office visits and hip replacements in Australia, Canada, France, Germany, the United Kingdom, and the United States. We also compared physicians' incomes net of practice expenses, differences in financing the cost of medical education, and the relative contribution of payments per physician and of physician supply in the countries' national spending on physician services. Public and private payers paid somewhat higher fees to US primary care physicians for office visits (27 percent more for public, 70 percent more for private) and much higher fees to orthopedic physicians for hip replacements (70 percent more for public, $\mathbf{1 2 0}$ percent more for private) than public and private payers paid these physicians' counterparts in other countries. US primary care and orthopedic physicians also earned higher incomes $\mathbf{( \$ 1 8 6 , 5 8 2}$ and $\$ 442,450$, respectively) than their foreign counterparts. We conclude that the higher fees, rather than factors such as higher practice costs, volume of services, or tuition expenses, were the main drivers of higher US spending, particularly in orthopedics.

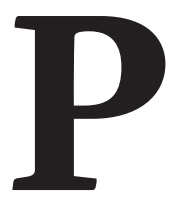

hysician spending per capita in the United States is much higher than in other countries. In 2008 per capita spending on physician services in the United States was $\$ 1,599$ (Exhibit 1), while per person spending for these services across all other Organization for Economic Cooperation and Development (OECD) countries averaged just $\$ 310$ per person (in US dollars, adjusted for purchasing power parities)-81 percent below the US figure. ${ }^{1,2}$

The differential in spending on physician services is greater than the overall difference in total health spending between the United States and other nations. ${ }^{2}$ One potential reason for this is that physicians are paid more per service in the United States than elsewhere.
In general, higher prices are said to be the primary reason for higher US health spending. As Gerard Anderson and others have observed, "It's the Prices, Stupid!" 3,4 Yet some analysts in the United States have suggested that the prices for some kinds of services, such as primary care, are not high enough. ${ }^{5}$

Building on the work of Anderson, ${ }^{4}$ Mark Pauly, ${ }^{6}$ Victor Fuchs and James Hahn, ${ }^{7}$ and the International Federation of Health Plans, we sought to produce a finer-grained and updated analysis of spending, fees, and earnings among physicians in different countries. While recognizing that full comparability is close to impossible, we compared fees, incomes, and spending for a subset of physicians. We focused on two areas of medicine and two specific physician
DOI: $10.1377 /$ hlthaff.2010.0204 HEALTH AFFAIRS 30 NO. 9 (2011): 1647-1656 C2011 Project HOPEThe People-to-People Health Foundation, Inc.
Miriam J. Laugesen(ml3111@ columbia.edu) is an assistant professor of health policy and management at the Mailman School of Public Health, Columbia University, in New York City.

Sherry A. Glied is a professor of health policy and management at the Mailman School of Public Health. She is currently on leave at the Department of Health and Human Services (HHS), where she is assistant secretary for planning and evaluation. This paper was written prior to her appointment at HHS and does not reflect the official views of $\mathrm{HHS}$. 
services: basic office visits provided by primary care physicians, and hip replacements provided by orthopedic surgeons, in Australia, Canada, France, Germany, the United Kingdom (England), and the United States.

We compared the price of these services in the United States with the prices paid by national or price-regulated insurance plans and by private insurers-where these exist-in the comparison countries. To address confounding factors, the study also compared physicians' incomes net of practice expenses (thus adjusting for differences in practice costs). We also took into account differences in the sources of financing of the cost of physician education. Finally, the study assessed the relative contribution of payments per physician and of physician supply in the countries' national spending on physician services.

\section{Challenges And Approaches}

CHALLENGES Understanding and comparing data on physician services is challenging because the category of physician services spending includes an array of physicians whose day-to-day work varies tremendously, even within countries. Likewise, the bundles of services included in fees may vary across countries.

Data must be pieced together from disparate, often conflicting sources. In many countries, physicians may be paid different fees by different patients, and prior studies do not separate these. Even if data were comparable, higher fees per service might reflect differences in practice expenses, such as malpractice costs, which vary across countries. Higher incomes might reflect differences in the level or source of financing of medical education.

In spite of these challenges, developing estimates of differences in public and private prices for physician services is useful. Although the point estimates are imprecise, evidence of the general direction and magnitude of differences, and of the sources of these differences, can provide a better understanding of the reasons for cross-national spending differences.

Physician AND COUNTRY Selection Primary care physicians were chosen because they provide the largest share of medical care in all countries. Using the OECD's 2008 definition of a generalist physician, this study defined a primary care physician as one who does not limit practice to certain disease categories. In the United States this definition includes family practice, general practice, internal medicine, obstetrics and gynecology, and pediatrics. ${ }^{8}$

Services provided by primary care physicians are broadly comparable, but there are some differences across countries. The scope of primary care practice varies across countries; it is narrower in the United States than in Australia or the United Kingdom. ${ }^{9}$

The main cost factor associated with primary care practice is the length of the physician visit. In general, physician visits in the United States are somewhat longer than in most other countries. Differences in primary care fees between the United States and other countries may, in part, reflect this difference in visit length. ${ }^{10}$

Orthopedic surgery was selected from among all the surgical subspecialties for three reasons. First, the main procedures performed by orthopedic surgeons are relatively standardized and are performed in similar ways across the countries under study. Second, the practice of orthopedic surgeons includes a large component of elective surgery. In countries where the government or health insurers ration access to elective surgery, the supply of orthopedic surgeons is often limited. Thus, this is an area where differences in supply may be an important contributor to differences in total expenditures.

Third, because orthopedic surgery is elective and the supply is often constrained in the public sector, in countries where physicians are allowed to charge private payers more than the government health plan pays (in so-called two-tier practices), orthopedic surgeons constitute a large share of physicians who elect to do so; see the online Appendix. ${ }^{11}$ Therefore, both private and public fees across countries can be readily compared.

The comparison countries chosen all have populations in excess of twenty million and have a per capita gross domestic product (GDP) that is 70-84 percent of the US level (Exhibit 1).

SYSTEM CHARACTERISTICS AND PHYSICIAN REIMBURSEMENT Information on US and comparison-country health care systems and payment practices was available from the OECD database ${ }^{2}$ and through a broad variety of other sources described below.

The health care systems of the six countries considered differ in many respects (Exhibit 2). ${ }^{2}$ Yet there is surprisingly little systematic variation in the structure of physician payment between the United States and the comparison countries.

Although the use of fee-for-service payment is often singled out as a source of higher US costs, all of the comparison countries except the United Kingdom continue to rely primarily on this payment method, particularly in the outpatient setting. Most other countries, however, have moved further away from fee-for-service than the United States has, by incorporating elements of quality-related bonuses, incentive pay, or bundling in their national insurance 
Health Care Spending, Physician Supply, And Demographic Characteristics In Six Countries, 2008

\begin{tabular}{|c|c|c|c|c|c|c|}
\hline & Australia & Canada & France & Germany & United Kingdom & United States \\
\hline \multicolumn{7}{|l|}{ TOTAL HEALTH SPENDING } \\
\hline Spending per capita & $\$ 3,353$ & $\$ 4,079$ & $\$ 3,696$ & $\$ 3,737$ & $\$ 3,129$ & $\$ 7,538$ \\
\hline Spending as percent of GDP & $8.4 \%$ & $10.4 \%$ & $11.2 \%$ & $10.5 \%$ & $8.7 \%$ & $16.0 \%$ \\
\hline \multicolumn{7}{|c|}{ PERCENTAge OF TOTAL hEALTH SPENDING, BY SOURCE } \\
\hline Ambulatory care & $37.7 \%$ & $28.9 \%$ & $28.4 \%$ & $30.8 \%$ & $-^{a}$ & $36.0 \%$ \\
\hline Percent provided in physician offices & 14.6 & 14.7 & 11.7 & 15.8 & $-^{a}$ & 21.2 \\
\hline Hospital services & 39.9 & 28.9 & 35.0 & 29.4 & $-^{a}$ & 32.9 \\
\hline Pharmaceuticals & 14.3 & 17.2 & 16.4 & 15.1 & $11.8 \%$ & $11.9 \%$ \\
\hline \multicolumn{7}{|l|}{ PHYSICIAN SUPPLY } \\
\hline Professionally active physicians per 1,000 & 3.2 & 2.3 & 3.4 & 3.9 & 2.6 & 2.6 \\
\hline \multicolumn{7}{|l|}{ POPULATION AND WEALTH } \\
\hline Total population (thousands) & 21,432 & 33,095 & 61,840 & 82,110 & 60,520 & 304,483 \\
\hline Percent over age 65 & $13.3 \%$ & $13.9 \%$ & $16.6 \%$ & $20.3 \%$ & $15.8 \%$ & $12.8 \%$ \\
\hline Percent under age 14 & $19.3 \%$ & $16.7 \%$ & $18.3 \%$ & $13.7 \%$ & $17.8 \%$ & $20.2 \%$ \\
\hline Per capita GDP & $\$ 39,439$ & $\$ 39,288$ & $\$ 33,134$ & $\$ 35,436$ & $\$ 36,128$ & $\$ 47,193$ \\
\hline
\end{tabular}

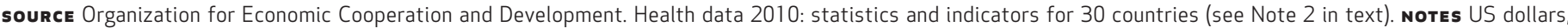

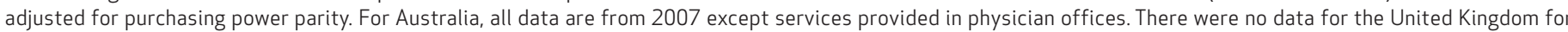
professionally active physicians, so data from practicing physicians were substituted. GDP is gross domestic product. ${ }^{a}$ Data were not available.

EXHIBIT 2

Health System And Physician Payment Features In Six Countries, 2008

\section{Primary care}

$\begin{array}{lll}\begin{array}{l}\text { Country } \\ \text { Australia }\end{array} & \begin{array}{l}\text { Universal } \\ \text { coverage? } \\ \text { Yes }\end{array} & \begin{array}{l}\text { Payment } \\ \text { mechanism } \\ \text { Fee-for-service }\end{array} \\ \text { Canada } & \text { Yes } & \begin{array}{c}\text { Fee-for-service/ } \\ \text { salary }\end{array} \\ \text { France } & \text { Yes } & \begin{array}{c}\text { Fee-for-service } \\ \text { Germany }\end{array} \\ & \text { Yes } & \begin{array}{c}\text { Fee-for-service, } \\ \text { but some } \\ \text { bundled } \\ \text { payments }\end{array} \\ \text { United Kingdom } & \text { Yes } & \begin{array}{c}\text { Salary with } \\ \text { incentives }\end{array} \\ & & \text { Seniors } \\ \text { only } & \begin{array}{c}\text { Fee-for-service/ } \\ \text { mixed }\end{array}\end{array}$

May charge above the
public fee schedule?
Yes-about $20 \%$ do
No

Some, but rare-some limits on rates

Yes-for privately insured patients

Some-no limits on rates

No for publicly insured patients; otherwise, private insurance rates differ from public rates; no limits on charges for privately insured patients outside insurer contracts

Orthopedic surgery covers portion of fees

Payment May charge above the mechanism public fee schedule?

Fee-for- Yes service

Fee-forservice/ salary

Fee-forservice

Salary

Salary

Fee-forservice/ mixed

No

Yes-some limits on rates specialists may receive extra pay

Yes-no limits on rates patients; otherwise, private insurance above the public schedule?

Yes

No

No-but some top Yes

Yes-

sometimes negotiated with providers

No for publicly insured rates differ from public rates; no limits on charges for privately insured patients outside insurer contracts
Public and privately negotiated rates differ 
physician payment systems, particularly for patients with chronic illnesses.

The other important structural difference is the role of private insurance in relation to government-established fee schedules. In the United States, private insurers are not required to use Medicare rates. In the comparison countries other than Canada, physicians may charge fees higher than those set by the government to some or all of their patients.

In France and Germany, there are limitations on the additional fees that may be charged; however, some physicians can charge higher fees to at least a subset of patients (all patients in France, privately insured patients in Germany) for outpatient services. Where physicians may charge fees above the national schedule, the practice is consistently more common among orthopedic surgeons than among primary care physicians, regardless of country.

\section{Analysis And Findings}

Under fee-for-service payment, total expenditures on physician services are the product of physician fees per service, the number of services provided by each physician, and the supply of physicians. These expenditures, in turn, compensate for practice expenses and for the time and skill of physicians. Expenditures must also compensate for the costs physicians incur in the course of receiving their education.

Physician fees Exhibit 3 provides information on the first piece of this equation: the public and private fees received for selected procedures across countries.

Public-sector physician payment rates are readily available from government websites in most countries. Wherever possible, rates for office visits reported below refer to a standard eleven-to-fifteen-minute office visit for an "established patient" (typically this would be a patient a physician had seen previously). However, not all countries provided this level of granularity in data.

Overall, publicly established fees for basic primary care office visits ranged from \$34 in Australia to $\$ 66$ in the United Kingdom. The US Medicare program paid at the mid-to-high end of this scale for a comparable visit: above the level in many countries, about equal to the level in Canada, but below the level in the United Kingdom.

Public program fees for uncomplicated, initial hip replacement surgeries (not revision surgeries) ranged from $\$ 652$ in Canada and $\$ 674$ in France to $\$ 1,634$ in the United States. The difference in public program fees is roughly comparable to the difference in national health spending across these countries.

EXHIBIT 3

Primary Care And Orthopedic Surgery And Fees In Six Countries, 2008

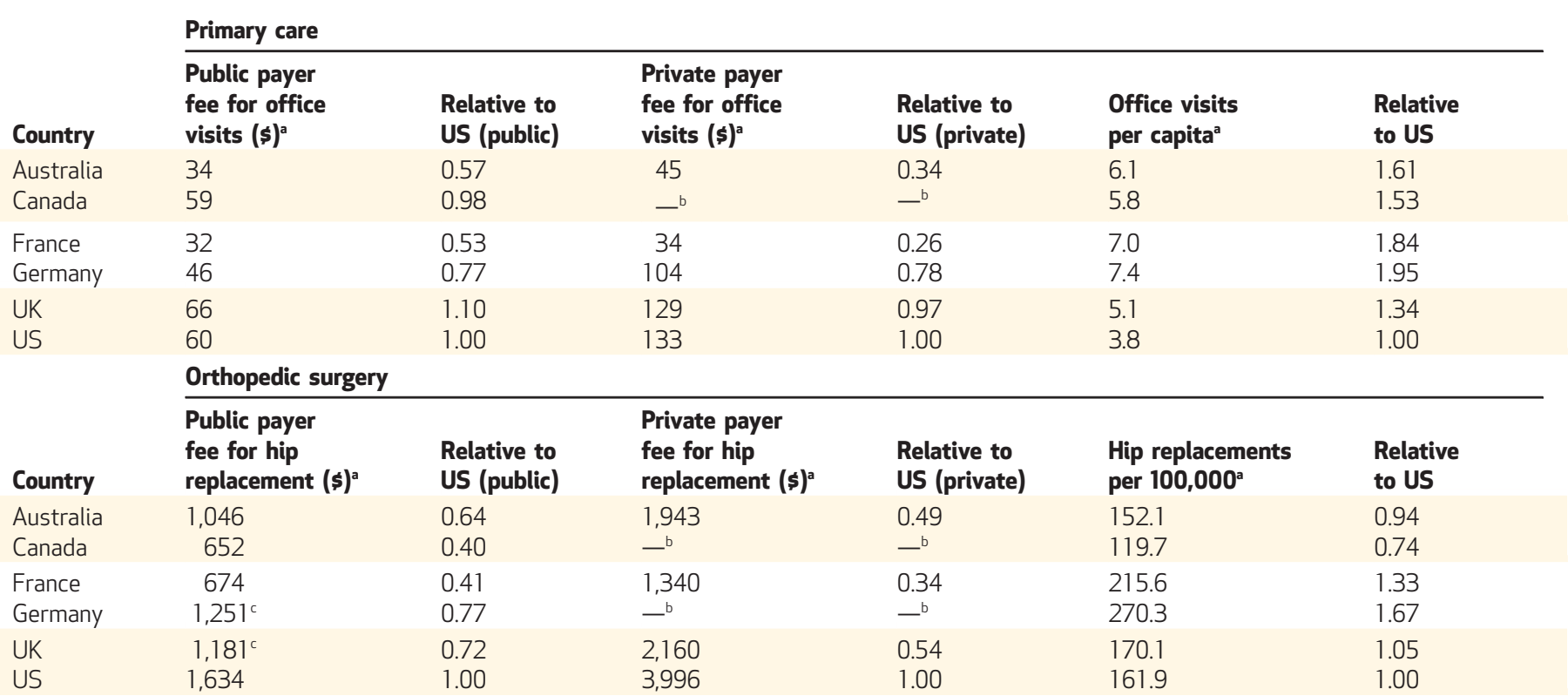


In countries that permit physicians to charge amounts other than the public fees (all except Canada), the market for private primary care physician consultations is relatively small, and the private fee mark-up is likewise limited. Data on private fees are more difficult to obtain than data on public fees are, and private payment rates typically vary within each country.

In Australia, the Australian Medical Association recommended a fee of US $\$ 45$ (2008 dollars) for an office visit (in 2004), although most private practice physicians did not charge this much. ${ }^{12}$ Private-practice physicians in France typically charge about 5 percent over the public schedule. In the United Kingdom, private primary care practices, which exist in large centers, require an enrollment fee (of about £30) and then charge a per visit fee. ${ }^{13}$ Physicians in Germany may charge privately insured patients for each separate service they render during an office visit.

In the United States, data on private insurance payment rates are proprietary and, therefore, almost impossible to obtain. They vary greatly among markets and among payers in a given market. ${ }^{14}$

Many physicians are paid under contracts negotiated with private insurers. A recent review of these rates by specialty type (not service) paid by four large national insurers in six markets found that primary care fees averaged about one-third above Medicare rates, while fees for orthopedic surgeons averaged about 50 percent above Medicare rates. ${ }^{14}$ Smaller health plans may have less negotiating power than large national insurers and therefore the amounts they pay physicians may be higher. Also, physicians may see patients who are covered by insurers with which they do not have contracts.

The data reported here were obtained from HealthGrades (http://www.healthgrades.com), which collected and disseminated information from eighty health plans by service type at the regional level during much of 2009.

Private insurers in the United States pay higher rates for primary care office visits in the United States than in other countries. However, private-insurer rates for primary care visits reported on HealthGrades for the United States are only slightly higher than private-insurer rates in the United Kingdom. Rates reported by Paul Ginsburg ${ }^{14}$ are below private-insurer rates in some other countries.

The market for private orthopedic services is larger overall, but it varies from country to country. In Germany, surgeons are salaried, and there is only a small market for private orthopedic surgery practice. In Australia and France, physicians may charge beyond the government fee schedule for private hip replacement surgery. Orthopedic surgeons in Australia often charge rates suggested by the Australian Medical Association, but these rates are not publicly available.

In France, surgeons negotiate rates with patients. They "may charge $€ 400-€ 3,000$ [US $\$ 560$ $\$ 4,198]$ in extra fees, and this is often the subject of tense debate" (personal communication from Michel Naiditch, Institut de Recherche et Documentation en Economie de la Santé, 2009). In both Australia and France, a portion of these extra fees is generally paid by supplementary insurance.

The United Kingdom has a thriving market in private orthopedic surgery. In some cases, private insurers negotiate rates with surgeons and private hospitals (or private units in public hospitals). There are also web-based services (for example, http://www.privatehealth.co.uk) that offer directories of private surgery providers, often with price information. In many instances, hospitals offer a bundled price for the surgery, including room fees, surgeon fees, and anesthesiologist charges.

Private health insurance fees for hip replacement surgery in the United States reported by HealthGrades are nearly $\$ 4,000$ per procedureabout twice as high as the private rate in any of the comparison countries. The orthopedic surgeon payment rates reported by Ginsburg ${ }^{14}$ also exceed those everywhere else.

Overall, fees paid by Medicare to US physicians for office visits are comparable to those paid by public insurers in several other countries, and fees paid by US private insurers are slightly higher than those paid by private insurers in other countries. In contrast, fees paid by public payers to orthopedic surgeons for hip replacements in the United States are considerably higher than comparable fees for hip replacements in other countries, and fees paid by private insurers in the United States for this service are double the fees paid in the private sector elsewhere.

VOLUMe OF SERVICES PROVIDED The second element in generating physician expenditures is the number of services provided per physician. As an approximation of this figure, Exhibit 3 reports the number of services provided per capita (column 6). ${ }^{15}$ There is somewhat less variation in the volume of services received by patients across countries compared to the variation in fees.

As an indication of primary care practice volume, data on the number of office visits per capita were used. The median number of office visits per capita was 5.95, with the United States well below the average across countries at 3.8.

The number of hip replacements per capita 
was used as an indication of orthopedic surgery volume. Hip replacement rates per 100,000 people ranged from a low of 119.7 in Canada (which has a limited supply of surgeons and a relatively young population) to a high of 270.3 in Germany (where the population is older and supply is not restrictive). In general, Americans are very low users of office visits and relatively high users of hip replacement surgery.

PHYSICIAN INCOME Volume and price combine to generate physician revenue, and subtracting practice expenses from this total yields net physician income. Exhibit 4 reports differences in annual pretax earnings net of practice expenses for primary care physicians and orthopedic surgeons (in US dollars, converted using purchasing power parity rates).

US primary care physicians earned the highest incomes $(\$ 186,582)$, while French $(\$ 95,585)$ and Australian $(\$ 92,844)$ primary care physicians had the lowest. Although payments to primary care physicians were greater in the United States than elsewhere, the differential was smaller than would be expected given the costliness of the overall US health care system.

Among orthopedic surgeons, those who had the highest annual pretax incomes, net of expenses, were in the United States (US $\$ 442,450)$. Among comparison countries, the United Kingdom led with pretax incomes net of expenses that were 50 percent higher than in other comparison countries (US\$324,138) but still about one-quarter less than US incomes. Annual pretax earnings of orthopedic surgeons in other countries, after expenses, ranged from US $\$ 154,380$ (France) to US $\$ 208,634$ (Canada).

The ratio of orthopedic surgeon earnings to primary care earnings was also greater in the United States than in any of the other countries (Exhibit 4). In the United States, primary care doctors earned only about 42 percent as much as orthopedic surgeons earned. In Canada, France, and Germany, in contrast, primary care doctors earned at least 60 percent as much as orthopedic surgeons earned.

The difference in annual net incomes between US physicians and their peers in the comparison countries is roughly as large as, or larger than, the difference in fees, despite the relatively small differences in volumes of services provided across countries. The differences in incomes relative to fees provide more confidence in the overall comparability of the data. They suggest that higher US fees are a consequence not only of higher practice expenses, but also of higher rewards for the skill and time of physicians.

PHYSICIAN TRAINING AND EDUCATION The most important component of physician services is the skill-or human capital-of the physicians delivering them, which depends on the nature of medical education (in school) and subsequent on-the-job residency training. International comparisons of physician prices must, therefore, also consider differences in the length of time,

EXHIBIT 4

Physician Capacity, Earnings, And Spending In Six Countries, 2008

\begin{tabular}{|c|c|c|c|c|c|c|c|}
\hline Country & $\begin{array}{l}\text { Density } \\
\text { per } \\
10,000\end{array}$ & $\begin{array}{l}\text { Density } \\
\text { relative } \\
\text { to US }\end{array}$ & $\begin{array}{l}\text { Pretax earnings } \\
\text { net of expenses } \\
\text { (US\$ 2008) }\end{array}$ & $\begin{array}{l}\text { Earnings } \\
\text { relative } \\
\text { to US }\end{array}$ & $\begin{array}{l}\text { Payments } \\
\text { to MDs per } \\
1,000 \text { (\$) }\end{array}$ & $\begin{array}{l}\text { Payments to } \\
\text { MDs relative } \\
\text { to US }\end{array}$ & $\begin{array}{l}\text { Primary care MD } \\
\text { earnings relative } \\
\text { to orthopedic } \\
\text { surgeons (\%) }\end{array}$ \\
\hline $\begin{array}{l}\text { Australia } \\
\text { Canada } \\
\text { France } \\
\text { Germany } \\
\text { United Kingdom } \\
\text { United States }\end{array}$ & $\begin{array}{r}14 \\
10 \\
17 \\
10 \\
7 \\
10\end{array}$ & $\begin{array}{l}1.4 \\
1.0 \\
1.7 \\
1.0 \\
0.7 \\
1.0\end{array}$ & $\begin{array}{r}92,844 \\
125,104 \\
95,585 \\
131,809 \\
159,532 \\
186,582\end{array}$ & $\begin{array}{l}0.50 \\
0.67 \\
0.51 \\
0.71 \\
0.86 \\
1.00\end{array}$ & $\begin{array}{l}129,982 \\
125,104 \\
162,494 \\
131,809 \\
111,672 \\
186,582\end{array}$ & $\begin{array}{l}0.70 \\
0.67 \\
0.87 \\
0.71 \\
0.60 \\
1.00\end{array}$ & $\begin{array}{l}49 \\
60 \\
62 \\
65 \\
49 \\
42\end{array}$ \\
\hline \multicolumn{8}{|c|}{ ORTHOPEDIC SURGEONS } \\
\hline $\begin{array}{l}\text { Australia } \\
\text { Canada } \\
\text { France } \\
\text { Germany } \\
\text { United Kingdom } \\
\text { United States }\end{array}$ & $\begin{array}{l}0.45 \\
0.32 \\
0.34 \\
0.44 \\
0.28 \\
0.66\end{array}$ & $\begin{array}{l}0.68 \\
0.48 \\
0.52 \\
0.67 \\
0.42 \\
1.00\end{array}$ & $\begin{array}{l}187,609 \\
208,634 \\
154,380 \\
202,771 \\
324,138 \\
442,450\end{array}$ & $\begin{array}{l}0.42 \\
0.47 \\
0.35 \\
0.46 \\
0.73 \\
1.00\end{array}$ & $\begin{array}{r}8,442 \\
6,676 \\
5,249 \\
8,922 \\
9,076 \\
29,202\end{array}$ & $\begin{array}{l}0.29 \\
0.23 \\
0.18 \\
0.31 \\
0.31 \\
1.00\end{array}$ & $\begin{array}{l}-^{\mathrm{a}} \\
-^{\mathrm{a}} \\
-{ }^{\mathrm{a}} \\
-^{\mathrm{a}}\end{array}$ \\
\hline
\end{tabular}

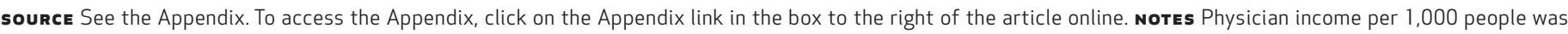

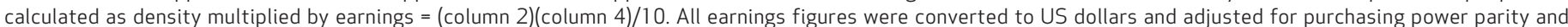

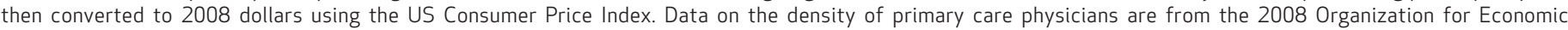

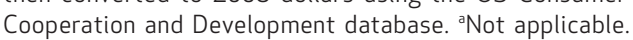


and in the amount of money, physicians spend pursuing their education and training.

The systems of physician education and training vary across the comparison countries. In some, entry to medical school occurs following high school graduation, rather than college. Admission to medical school is relatively easy in some countries; the difficult hurdle occurs at exams that take place after the first or second year of study. In other countries, matriculation is the main barrier to admission.

Despite these differences, there has been considerable convergence in the most straightforward measure of physician education and training-the number of years of education required after high school-across the five countries; see the Appendix ${ }^{11}$ Education and training in primary care generally takes about nine to eleven years after high school graduation. In most countries, orthopedic specialty education and training takes twelve to thirteen years to complete after high school. A proportion of orthopedic surgeons in all countries choose to complete further specialized fellowships.

In all countries, the largest cost of medical education and training is the opportunity cost of forgone earnings during medical school and subsequent training. These costs vary depending on the length of time physicians spend in school and on-the-job training and on the earnings a trainee physician could earn in other occupations. In all countries studied, these costs are incurred by future physicians themselves.

An important distinction between other countries and the United States is that in most other countries, the bulk of the tuition cost of medical education (as well as of undergraduate education) is borne by the public sector. In the United States, many medical students must pay their own tuition costs, although the federal government does fund graduate medical education through payments to academic medical centers. The need to recoup these direct costs implies that US physicians would be expected to earn more than physicians in countries where tuition is free-even if the forgone opportunity costs of medical education and training were the same in all countries (and they might not be, as noted below).

Estimating the amount of earnings needed to recoup the tuition cost of medical education requires estimating the total cost to the individual physician of his or her education, and this is calculated based on the following assumptions. First, because medical school is completed after four years of undergraduate education, a tuition cost of $\$ 12,000$ per year for four undergraduate years is used. ${ }^{16}$ The cost of medical school averages between $\$ 26,814$ at public medical schools and $\$ 45,448$ at private ones-an average of about $\$ 35,000$ per year. ${ }^{17}$

Over the eight years of post-high school education, at an interest rate of 7 percent, an American medical student would have incurred as much as $\$ 225,000$ in tuition expenses by medical school graduation. In 2009, 87 percent of medical graduates left medical school with graduate educational debt, and 38 percent had undergraduate medical debt. The mean debt US medical students graduated with in 2009 was $\$ 156,456$. . $^{18}$

The debt medical students incur is lower than the total cost of medical education. However, the estimated total tuition cost is used for the estimates because economists assume that people try to recoup the total cost of education rather than the portion of it financed through debt. This investment would need to be amortized over the period starting with the completion of a medical residency.

If a physician practiced for thirty-five years (based on a present-value formula), the additional earnings, net of expenses, required to pay off this investment would amount to about $\$ 21,300$ per year for a primary care physician and about $\$ 24,400$ per year for an orthopedic surgeon. ${ }^{19,20}$

Although the tuition cost of medical education in the United States borne by individuals is substantial, it cannot fully account for the observed differences between the earnings of US physicians and physicians in all other countries. The difference between annual net incomes, after practice expenses, of primary care physicians in the United States and in the second most costly country, the United Kingdom, is $\$ 27,000-$ somewhat more than the estimated $\$ 21,300$ per year of practice required to recoup the average tuition investment in education. The difference between the annual net incomes of orthopedic surgeons in the United States and the United Kingdom is $\$ 118,000-$ nearly five times the estimated $\$ 24,400$ difference in investment repayment costs.

COMPARING CAPACITY AND EXPENDITURES The final component in generating aggregate physician expenditures is the supply of primary care and orthopedic physicians, measured here as density of physicians in relation to population during the mid-2000s (Exhibit 4). The United Kingdom had the lowest density of primary care physicians. Canada, Germany, and the United States had somewhat more primary care doctors relative to their populations, and Australia and France had 40 percent and 70 percent, respectively, more such physicians than did the United States.

Most of the countries examined here had 
0.3-0.4 orthopedic surgeons per 10,000 people. Canada had slightly fewer relative to its population. Compared to the other countries in the study, the United States and Germany had nearly twice as many surgeons per 10,000 people.

The effects of variations in physician supply and earnings on expenditures for physician services (Exhibit 4) may offset or amplify each other. In primary care, these effects tended to be offsetting. Although there is considerable variation in both supply and earnings, overall net payments to primary care physicians outside the United States fell within a fairly narrow range-between $\$ 111,672$ in the United Kingdom and $\$ 162,494$ per 1,000 population in France. Spending in the United States was somewhat greater, at about $\$ 185,000$ per 1,000 population.

On average, net payments to primary care physicians in the other five countries were 29 percent lower than the payments in the United States-a differential about half as large as the difference between overall health spending in the United States and these other countries.

In orthopedic surgery, in contrast, differences in supply and payments tended to amplify one another. Net payments per 1,000 population to orthopedic surgeons in the comparison countries ranged between $\$ 5,249$ in France to $\$ 9,076$ in the United Kingdom. However, they were more than $\$ 29,000$ in the United States. The average payment to orthopedic surgeons in the other five countries was $\$ 7,673$-only about one-quarter as high as in the United States. This differential is about twice as large as exists in overall spending.

\section{Discussion}

American primary care and orthopedic physicians are paid more for each service than are their counterparts in Australia, Canada, France, Germany, and the United Kingdom. The extent of higher payment is not entirely explained by differences in practice expenses, because net incomes vary by about as much as fees do.

For the particular services examined here, higher US incomes do not appear to be due to a higher volume of services. The difference in net incomes exceeds the differential in privately accrued tuition costs between countries. This relationship suggests that higher fees, rather than higher practice costs, volumes, or tuition expenses, are the main driver of higher US spending in these two areas.

Price comparisons are challenging, but one indicator of the validity of the price data used is that they are consistent with cross-national earnings data. US primary care physicians earn about one-third more than do their counterparts elsewhere. However, neither public insurance nor private insurance generalist physician fees for basic office visits are much higher in the United States than in many of the comparison countries.

Instead, US primary care doctors do somewhat better overall mainly because a much larger share of their incomes is derived from private insurance. In other countries where private primary care practice is permitted, the market share of this form of practice is relatively small.

For orthopedic surgeons, the story is quite different. US orthopedic surgeons earn much higher incomes than do their counterparts abroad, and there are more such surgeons per capita here than almost anywhere else. In consequence, comparison countries spend only about one-quarter as much as the United States spends on orthopedic surgeons.

Rates of hip replacement surgery are not higher in the United States than elsewhere, although rates of other procedures performed by orthopedic surgeons may be. Much of the difference in earnings appears to be due to differential fees. Public-sector fees for hip replacement surgery in other countries are about half as high, on average, as Medicare fees in the United States.

Private-sector fees abroad are only about onethird to one-half as high as private-insurer fees in the United States. Orthopedic surgeons' incomes tend to be higher in those comparison countries where private practice is permitted. However, it is notable that even in these countries, private fees are generally lower than in the United States, in parallel with lower public fees.

One explanation for the higher incomes of US physicians may lie in the broader US income structure. The share of income received by people in the top 1 percent of the US income distribution far exceeds the corresponding share in the comparison countries. ${ }^{21}$ These higher earnings may mean that the earnings forgone by medical students during their medical education and training are relatively higher in the United States. They certainly indicate that the alternative opportunities available to prospective physicians are more lucrative in the United States. ${ }^{22}$

When physician fees in each of the comparison countries are compared to the mean incomes of the top 1 percent of households in that country, the results are broadly consistent across countries. Primary care physicians in other countries earn about one-third as much as the average income of the top 1 percent households, while orthopedic surgeons earn between half (in Canada) and 90 percent (in the United Kingdom) as much. The United States, at three-quarters, is in 
the middle of the pack. High physician fees in the United States may reflect the cost of attracting skilled candidates to medicine in a society with a relatively more skewed income distribution.

\section{Conclusions}

This study examines, in greater detail than previously attempted, the well-known finding that an important driver of the relatively higher cost of health care in the United States is higher prices. Such ambitious cross-country comparisons as those made here are challenging, and the quality and quantity of data available to perform them is variable. However, our findings as a whole suggest that the observed price differentials are not entirely a consequence of differences in underlying practice costs or in the tuition costs of medical education. Rather, three other factors that affect prices seem most important.

First, the ratio of public payment rates for office visits compared to hip replacements is relatively low in the United States. Second, private insurers in the United States have been less suc- cessful in negotiating fees with orthopedic surgeons than with generalist physicians. Third, the medical care delivery sector cannot be fully separated from the rest of the economy: Physicians everywhere are drawn from the peak of the educational distribution, and their earnings reflect the cost of drawing highly skilled people to the profession in an economy where the rewards for skilled individuals are higher than elsewhere.

For decades, concern has been raised that greater financial incentives may be needed so that enough American doctors will choose to become primary care physicians. Our analysis suggests that policy makers in all countries need to consider how differential prices paid by both public- and private-sector payers to specialists influence specialty choices. Furthermore, this analysis suggests a need for greater standardization of cross-national data on the nature of physician services provided, fees, education, and incomes to allow ongoing comparative research on the relationship between prices and health care spending growth.
Financial support for this paper for Miriam J. Laugesen was provided by an Investigator Award in Health Policy Research from the Robert Wood Johnson Foundation, Princeton, New Jersey; and partial financial support for this paper for Sherry A. Glied was provided by a grant from the Commonwealth Fund. Glied is employed by the Department of Health and Human Services (HHS). This paper was written prior to her appointment at HHS and does not reflect the official views of HHS. This paper relied heavily on the assistance of Eric Black, Katy Luo, Arielle Rodman, and Aliya Sanders. The authors could not have written it without the country-specific wisdom of
Jane Hall and Ankit Kumar (Australia); Gerard de Pouvourville and Francoise Simon (France); Volker Amelung, Mirella Cacace, and Katharina Janus (Germany); Martin Roland (United Kingdom); and Rick Kronick (United States). The authors are grateful to Robin Osborn and Cathy Schoen for their very useful (and detailed) comments.

\section{NOTES}

1 Organization for Economic Cooperation and Development. OECD.StatExtracts [database on the Internet]. Paris: OECD; 2011 [cited 2011 Aug 4]. Available from: http:// stats.oecd.org

2 Organization for Economic Cooperation and Development. OECD health data 2010: statistics and indicators for 30 countries. Paris: OECD; 2010.

3 Garber AM, Skinner J. Is American health care uniquely inefficient? J Econ Perspect. 2008;22(4):27-50.

4 Anderson GF, Reinhardt UE, Hussey PS, Petrosyan V. It's the prices, stupid: why the United States is so different from other countries. Health Aff (Millwood). 2003;22(3):89-105.

5 Bodenheimer T, Berenson RA, Rudolf $\mathrm{P}$. The primary care-specialty income gap: why it matters. Ann Intern Med. 2007;146(4):301-6.

6 Pauly MV. US health care costs: the untold true story. Health Aff (Millwood). 1993;12(3):152-9.

7 Fuchs VR, Hahn JS. How does Canada do it? A comparison of expenditures for physicians' services in the
United States and Canada. N Engl J

Med. 1990;323(13):884-90.

8 Organization for Economic Cooperation and Development. Health data, 2008. Paris: OECD; 2008.

9 Bindman $A B$, Forrest $C B$, Britt $H$, Crampton P, Majeed A. Diagnostic scope of and exposure to primary care physicians in Australia, New Zealand, and the United States. Br Med J. 2007;334(7606):1261.

10 Donelan K, Blendon RJ, Schoen C, Davis K, Binns K. The cost of health system change: public discontent in five nations. Health Aff (Millwood). 1999;18(3):206-16.

11 To access the Appendix, click on the Appendix link in the box to the right of the article online.

12 Wood M. Most GPs plan to raise private fees. The Age. 2004 Oct 31.

13 Private General Practice Services. Practice fees to August 12009 [Internet]. Leicester (UK): Private General Practice Services; 2009 [cited 2011 Aug 4]. Available from: http://www.privategp.com/fees

14 Ginsburg PB. Wide variation in hospital and physician payment rates evidence of provider market power. Washington (DC): Center for Studying Health System Change; 2010 Nov 16. (Research Briefs).

15 A more appropriate measure would be physician services rendered per physician, but these data are not available.

16 Department of Education. Table 320: average undergraduate tuition and fees and room and board rates [Internet]. Washington (DC): National Center for Education Statistics; 2007 [cited 2011 Aug 4]. Available from: http://nces.ed.gov/ programs/digest/d07/tables/ dt07_320.asp

17 Association of American Medical Colleges. Table 1: US medical schools, tuition and student feesfirst year students, 2009-2010 and 2008-2009 [Internet]. Washington (DC): AAMC; 2010 [cited 2011 Aug 4]. Available from: http:// services.aamc.org/tsfreports/ report_median.cfm?year_of_ study $=2010$

18 Association of American Medical Colleges. Medical student education: 
costs, debt, and loan repayment facts [Internet]. Washington (DC): AAMC; 2009 Oct [cited 2011 Aug 4]. Available from: http://www.aamc.org/ download/48760/data/debtfactcard .pdf

19 Glied S, Prabhu AG, Edelman N. The cost of primary care doctors. Forum
Health Econ Policy. 2009;12(1).

20 The annual payment required to pay off tuition costs is calculated using the standard amortization formula, available online at http://www .amortizationformula.org

21 Organization for Economic Cooperation and Development. Grow- ing unequal: income distribution and poverty in the OECD. Paris: OECD; 2008.

22 Cutler DM, Ly DP. The (paper) work of medicine: understanding international medical costs. J Econ Perspect. 2011;25(2):3-25.

\section{ABOUT THE AUTHORS: MIRIAM J. LAUGESEN \& SHERRY A. GLIED}

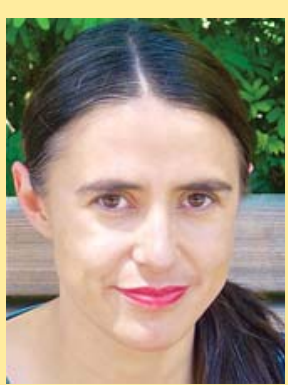

Miriam J. Laugesen

is an assistant professor of health policy and management at the Mailman School of Public Health,

Columbia

University.

In this month's Health Affairs, Miriam Laugesen and Sherry Glied compare physicians' fees for primary care office visits and hip replacements in six industrialized countries and show that higher fees in the United States are the main drivers of higher spending.

Laugesen says that the paper builds on work by Gerard Anderson and colleagues, published in Health Affairs, May/Jun 2003, that showed that higher prices for health care goods and services in the United States than abroad are a chief cause of high US health spending. "Anderson drew everyone's attention the fact that prices were higher, and the question was, which prices and in what way," Laugesen says. "The goal of our study was to go deeper and to focus on the physicians."

Laugesen is an assistant professor of health policy and management at the Mailman School of Public Health at Columbia University. She recently received a Robert Wood Johnson Investigator Award in Health Policy Research to study the evolution of physician payment under Medicare's resource-based relative value scale. Her cross-national work explores market reforms and cross-border health care, while her other research focuses on state health policies, including regulation of mandated insurance benefits and insurance expansions.

Laugesen earned a master's degree in political science from Washington University and a doctorate in political science from the University of Melbourne, in Australia.

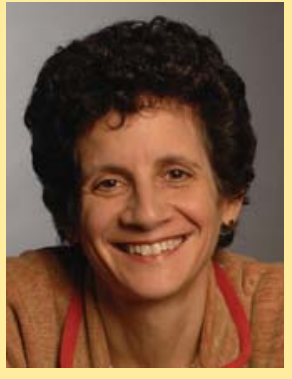

Sherry A. Glied is assistant secretary for planning and evaluation, Department of Health and Human Services.

Glied is assistant secretary of planning and evaluation at the Department of Health and Human Services. She is on leave from the Mailman School of Public Health at Columbia, where she is a professor of health policy and management A member of the Institute of Medicine, Glied is the author of Chronic Condition (Harvard University Press, 1998); coauthor, with Richard Frank, of Better but Not Well (Johns Hopkins University Press, 2006); and coeditor, with Peter Smith, of the Oxford Handbook of Health Economics (Oxford University Press, 2011).

Glied has a master's degree in economics from the University of Toronto and a doctorate in economics from Harvard University. 